
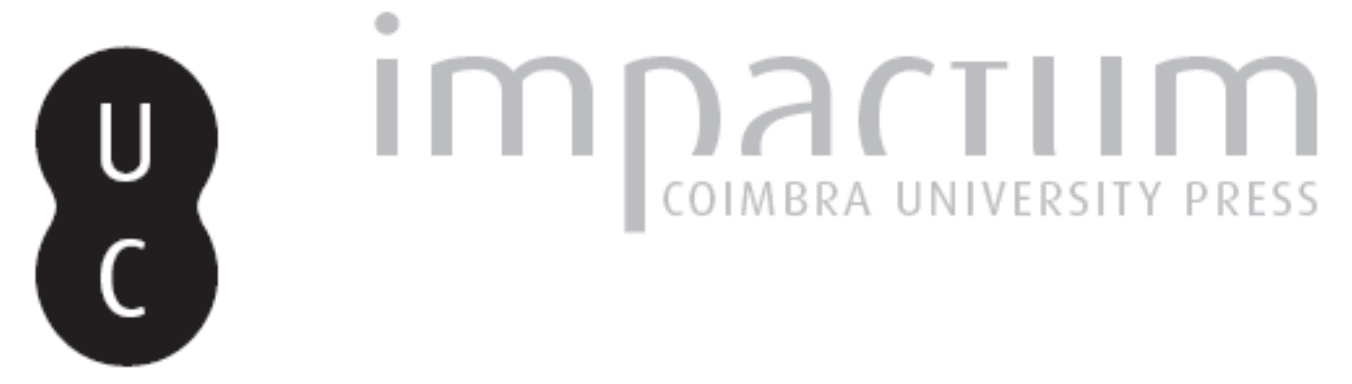

\title{
Aspectos forenses das lesões ortopédicas nos atropelamentos
}

Autor(es): $\quad$ Durão, $\mathrm{CH}$; Lucas, FM; Vieira, DN

Publicado por: Imprensa da Universidade de Coimbra

URL persistente:

URI:http://hdl.handle.net/10316.2/41086

DOI:

DOI:https://doi.org/10.14195/1647-8630_25_4

Accessed : $\quad$ 26-Apr-2023 12:59:08

A navegação consulta e descarregamento dos títulos inseridos nas Bibliotecas Digitais UC Digitalis, UC Pombalina e UC Impactum, pressupõem a aceitação plena e sem reservas dos Termos e Condições de Uso destas Bibliotecas Digitais, disponíveis em https://digitalis.uc.pt/pt-pt/termos.

Conforme exposto nos referidos Termos e Condições de Uso, o descarregamento de títulos de acesso restrito requer uma licença válida de autorização devendo o utilizador aceder ao(s) documento(s) a partir de um endereço de IP da instituição detentora da supramencionada licença.

Ao utilizador é apenas permitido o descarregamento para uso pessoal, pelo que o emprego do(s) título(s) descarregado(s) para outro fim, designadamente comercial, carece de autorização do respetivo autor ou editor da obra.

Na medida em que todas as obras da UC Digitalis se encontram protegidas pelo Código do Direito de Autor e Direitos Conexos e demais legislação aplicável, toda a cópia, parcial ou total, deste documento, nos casos em que é legalmente admitida, deverá conter ou fazer-se acompanhar por este aviso.

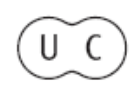




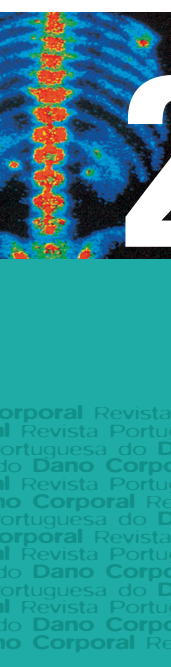

$$
\text { REVISTA PORTUGUESA }
$$
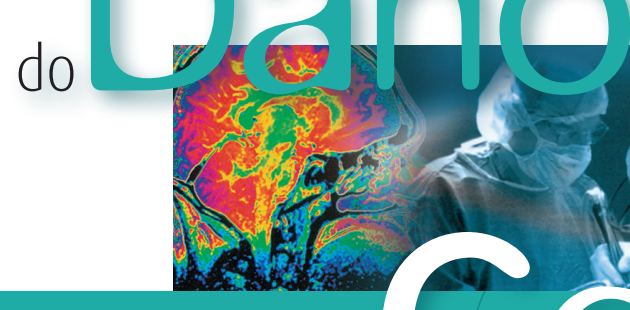

$\stackrel{2}{2}$

ż

$\stackrel{-}{\bar{z}}$

三

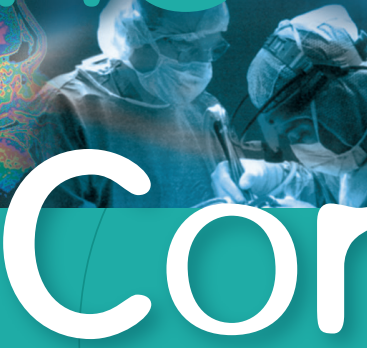

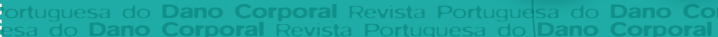

Dîn

esa do Dano Corporal Revista Portuguesa do Dano Corpora/ Revista Portuguesa do Dano Corporal

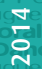

Corporal

岁

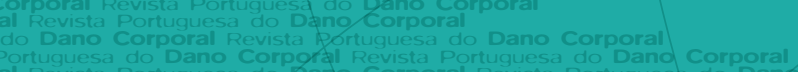

o Corporal Revista Portuguesa do Dano Corporal Revista Portuguesa do Dano Corporal

APADAC

ASSOCIAÇÃO PORTUGUESA

DE AVALIAÇÃO

DO DANO CORPORAL
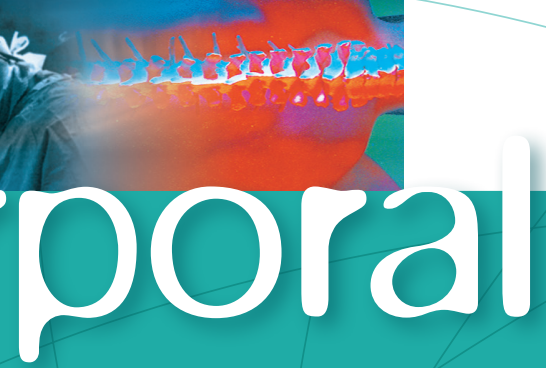


\section{Aspectos Forenses das Lesões Ortopédicas nos Atropelamentos}

Durão $\mathrm{CH}^{1,2}$, Lucas $\mathrm{FM}^{3}$, Vieira $\mathrm{DN}^{4}$

O atropelamento tem um sentido amplo, "passar por cima de algo", ou "empurrar violentamente alguém para abrir passagem". Em medicina legal é o impacto ou a sobre passagem de pessoas ou animais, de que podem resultar lesões e mortes. Normalmente, trata-se de acidente que gera ação civil ou penal contra o condutor, mas em alguns casos pode ser de etiologia suicida ou mesmo homicida.

Segundo Calabuig[1], os veículos atropeladores podem classificar-se em:

\section{A) Veículos com rodas desprovidas de pneus}

1. Veículos de tração animal: veículos primitivos utilizados nos trabalhos agrícolas e que ainda se encontram em algumas aldeias. Possuem baixa velocidade e uma relação inversa entre o peso e velocidade.

2. Veículos de trajeto obrigatório: representados pelos comboios e elétricos, tendo como características traumatológicas o deslizarem sobre trilhos, rodas de ferro com superfície de apoio plana e barra lateral, grande velocidade e peso. A diferença entre o comboio e o elétrico é notória. O primeiro é habitualmente composto por múltiplas carruagens, que acabam por produzir sucessivas lesões.

\footnotetext{
Hospital de Vila Franca de Xira

Gabinete Médico Legal de Torres Vedras

Centro Hospitalar da Universidade de Coimbra

Instituto Nacional de Medicina Legal
} 
\begin{tabular}{ll|l} 
Durão CH, Lucas FM, Vieira DN & 54
\end{tabular}

\section{B) Veículos com pneus}

1. Bicicletas: como agente material de atropelamento, caracteriza-se pela sua instabilidade, reduzido peso e baixa velocidade.

2. Motocicletas: veículos dotados de motor que podem atingir grandes velocidades e provocar atropelamentos de maior gravidade e com maior peso que as bicicletas.

3. Automóvel: como características resumidas destacam-se o peso, a velocidade e a manobrabilidade.

4. Veículos de grande tonelagem: camiões, autocarros ou veículos semelhantes, que podem atingir grandes velocidades e com potencial muito mais lesivo face a sua grande massa, peso e difícil manobrabilidade.

Entre os fatores que mais influenciam o potencial lesivo dos veículos atropelantes, situam-se:

1. Massa.

2. Velocidade (as duas juntas condicionam a energia cinética conforme a fórmula:

$\mathrm{E}=\frac{\mathrm{mv} 2}{2}$

3. Tipo de rodas.

4. Estabilidade.

5. Manobrabilidade.

A presença de partes salientes do veículo podem ainda imprimir lesões particulares nas vítimas, típicas de alguns mecanismos de atropelamento, tais como a marca em estrela da Mercedes Benz ou queimaduras pelas grades do radiador e lacerações por pára-choques[2,3].

\section{Lesões por atropelamento}

O atropelamento é considerado um traumatismo complexo. As lesões podem ter diversas ações (contundentes, cortantes, perfurantes e térmicas) e atuar de forma isolada ou associada dependendo das fases. Cada fase do traumatismo imprime determinado padrão de lesão com enorme interesse na abordagem do politraumatizado, que permite avaliar a magnitude da energia, reconstruir o acidente e valorizar as sequelas no dano corporal pós traumático. 


\section{Fases do atropelamento}

Regra geral, o atropelamento segue determinada sequência com 4 fases. Nem sempre essas fases se encontram totalmente presentes, o que nos permite distinguir algumas variedades como sendo típico completo ou incompleto $[2,3,4,5]$.

$\mathrm{O}$ atropelamento típico completo, desenvolve-se sequencialmente nas seguintes fases: colisão, queda, esmagamento e arrastamento.

Colisão: É caracterizada pelo contato mais ou menos violento do veículo com a vítima.O embate pode ser único ou múltiplo num breve espaço de tempo, por traumatismos sucessivos contra diferentes partes do veículo. A localização das lesões depende da relação entre as regiões do veículo que entram em contato com a vítima e a sua posição. São basicamente feridas de ação contundente, tais como escoriações, contusões e lacerações, que podem estar associadas com diferentes fraturas.

Pode ser subdividido numa fase de impacto primário e numa de impacto secundário[5]:

Impacto primário: corresponde ao traumatismo inicial que o veículo provoca no peão, geralmente nos membros inferiores. As lesões típicas são as produzidas pelo para-choquenos ossos da perna "bumper fracture"e tem- se modificado ao longo do tempo. Os pára-choques modernos deformam mais, fragmentando-se e dissipando energia, um conceito oposto aos dos pára-choques de outrora, mais resistentes e quase sempre de metal. No entanto, a maior distribuição das forças do impacto, embora produza fraturas de menor gravidade na diáfise da tíbia, aumenta o risco de lesões ligamentares e meniscais associadas.

A ausência de "bumper fracture" é comum quando a vítima é colhida pela região lateral do veículo, tal como acontece quando o sinistrado está no meio de dois veículos estacionados e projeta a cabeça antes da marcha. Nestas circunstâncias as lesões ocorrem diretamente na cabeça, com posterior queda para trás [2].

A tíbia e o perónio são os ossos mais atingidos durante o atropelamento. Burgesset al. salientaram a gravidade das fraturasda tíbia sofridas por peões e demonstraram que $93 \%$ deste tipo de lesões são causadas por impactos de alta energia, 30\% são bilaterais e 65\% são fracturas expostas tipo III de Gustilo. Os acidentes graves contribuem com 33\% dos casos e nestas circunstâncias os sinistrados sofrem lesões multi-sistêmicas (43\% apresentam lesões cranianas ou pélvicas[6]). Fraturas semelhantes são produzidas em idosos com osteoporose[7] por mecanismos de baixa energia. 
Geralmente o ponto do impacto na perna é mais baixo que a altura do para-choque, por vezes com fraturas logo acima do tornozelo, o que pode indicar uma tentativa de travagem, isto porque durante a travagem a frente do veículo tende a aproximar-se mais do solo $[2,3,8]$. Traumatismos em diferentes níveis de ambas as pernas, podem indicar que a vítima foi atingida enquanto caminhava ou corria, e neste caso, a perna com maior fratura costuma ser a que sustentava o peso do corpo durante o embate, apresentando quase sempre uma fratura cominutiva, segmentar, ou em espiral, pela acção de várias forças $[2,3,8,9]$

As fraturas da tíbia e do perónio resultantes de um traumatismo direto encontram-se ao mesmo nível e normalmente são de traço transverso ou com fragmento em asa de borboleta, com o ápice do triângulo apontando a direção em que o veículo viajava e a base do triângulo para o lado do impacto[2,8,9,10]. Conhecida como "Messerer fracture[11], a sua interpretação tem sido questionada.

A fratura diafisária da tíbia, habitualmente no terço médio, face a pouca cobertura de tecidos moles, tende a ser exposta, geralmente com a ferida no lado oposto ao traumatismo. As fraturas dos pratos tibiais também são frequentes e resultam de mecanismos varo/valgo, com dissociação metafiso-diafisária (tipo VI de Schatzker). As fracturas mais graves são frequentes nos acidentes de alta energia. [12] 


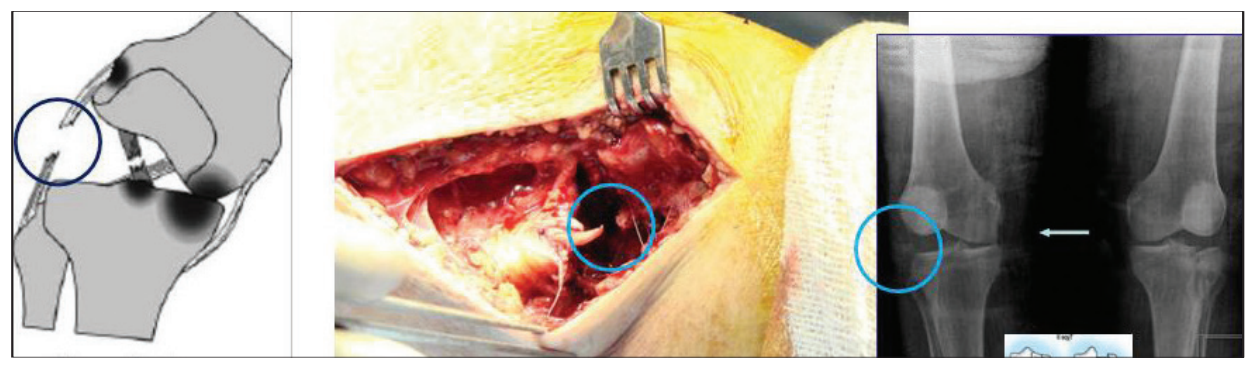

Figura 01. Traumatismo nos joelhos por atropelamento. A observação atenta permite interpretar que o embate ocorreu ao mesmo nível da esquerda para a direita, com forças de valgo produzindo uma fratura do prato tibial externo do joelho esquerdo e lesão do ligamento colateral lateral no joelho direito por forças em varo.
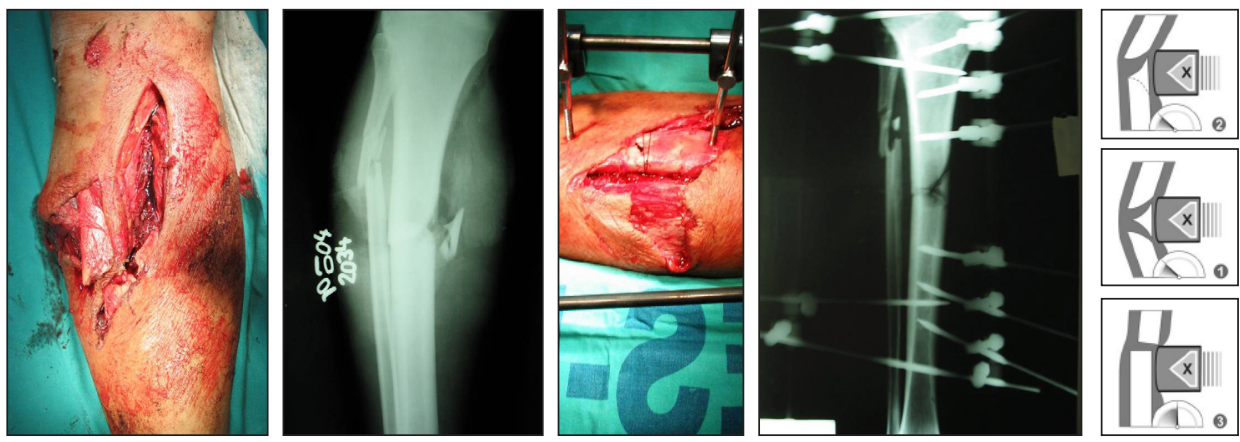

Figura 02. "Messerer fracture". A fratura da tíbia resultante de um traumatismo direto, com fragmento em asa de borboleta. O ápice do triângulo aponta a direção em que o veículo circulava e a base do triângulo para o lado do impacto.
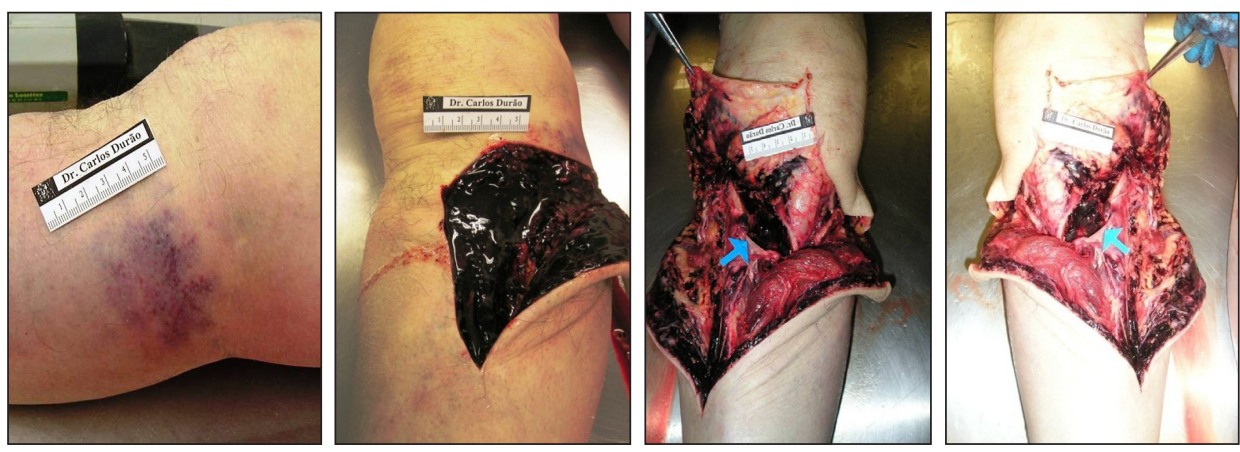

Figura 03. Fratura dos pratos tibiais do joelho direito. A equimose não traduz a gravidade das lesões associadas (Schatzker VI) por acção contundente. 
Impacto secundário: É o traumatismo do peão com o veículo, verificando-se quando a velocidade do veículo é superior aos $20 \mathrm{~km} / \mathrm{h}$. Tal embate pode ocorrer no para lamas, nas lanternas dianteiras, no capô ou na moldura do pára-brisa.[2,3,4,5] As lesões no peão costumam atingir a metade superior do corpo (fraturas da pelve, dorso, cabeça, coluna cervical). O impacto sobre as luzes dianteiras provoca lesões nas nádegas, face lateral das coxas, gerando um descolamento entre a camada mais densa do tecido adiposo e a mais frouxa, dando origem a uma nova cavidade com hematoma associado, conhecido como "descolamento traumático de Morell Lavallé", muitas vezes não diagnosticado na abordagem inicial[13].

1. Queda: Quando a velocidade do veículo é de 40 a $50 \mathrm{~km} / \mathrm{h}$ e o impacto primário se produz abaixo do centro de gravidade da vítima, esta escorrega pelo capô e cai ao solo. A lesão característica que ocorre na cabeça é do tipo "golpe e contra golpe", sendo nos membros superiores fraturas do punho, cotovelo ou úmero. Pode o peão cair sentado com traumatismo na região sacroilíaca. Outras vezes, a hiperextensão do pescoço, pela aceleração/desaceleração, pode produzir luxações ou fraturas, como a do processo odontóide[13].
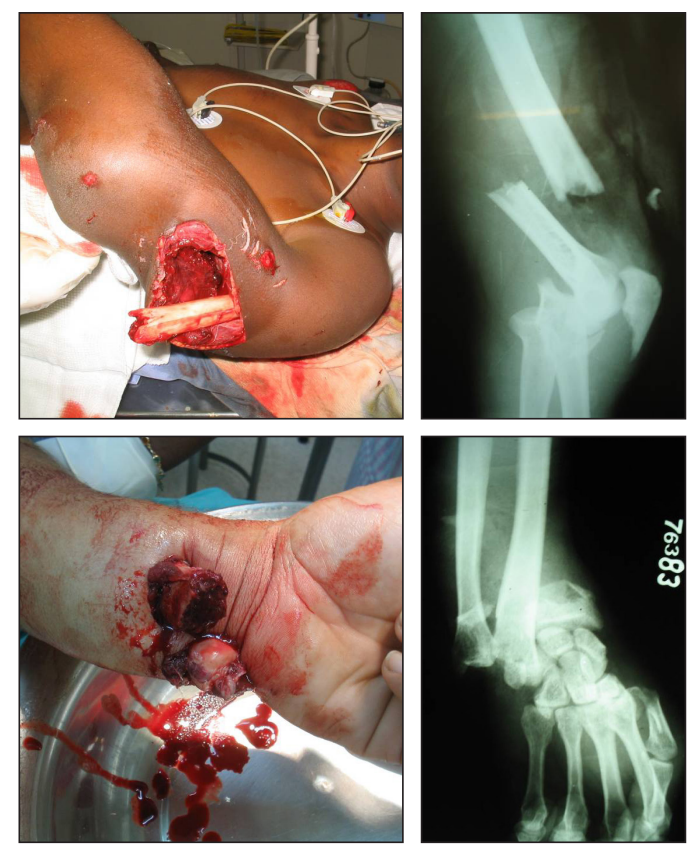

Figura 04. Fraturas expostas do cotovelo e do punho, são exemplos de lesões típicas pela queda durante o atropelamento. 
2. Esmagamento: Nos casos típicos, essa fase decorre em dois tempos.

a) O veículo avança sobre a vítima, que está no solo, atingindo-a e passando por cima, ou afastando-a para o lado.

b) Quando ocorre passagem por cima, o corpo da vítima é comprimido contra o solo pelas rodas ou outras partes do veículo, esmagando-o. O descolamento traumático, pode assumir grandes proporções com exposição dos planos mais profundos nos indivíduos mais obesos. Com a travagem, as rodas permanecem bloqueadas, propiciando lesões mistas de esmagamento e de arrastamento [9,13], facilmente identificáveis por um perito experiente, informação importante para a reconstrução da dinâmica do evento. Por vezes, marcas do pneu podem ficar impressas na pele ou roupa da vítima (estrias pneumáticas de Simonin).

As lesões variam segundo a natureza, gravidade e tipo de veículo. A intensidade do impacto pode provocar lesões ósseas e articulares, de localização variável, dependendo da região esmagada e pode mesmo triturar. As lesões cutâneas podem ser de pouca gravidade mas de grande valor pericial para
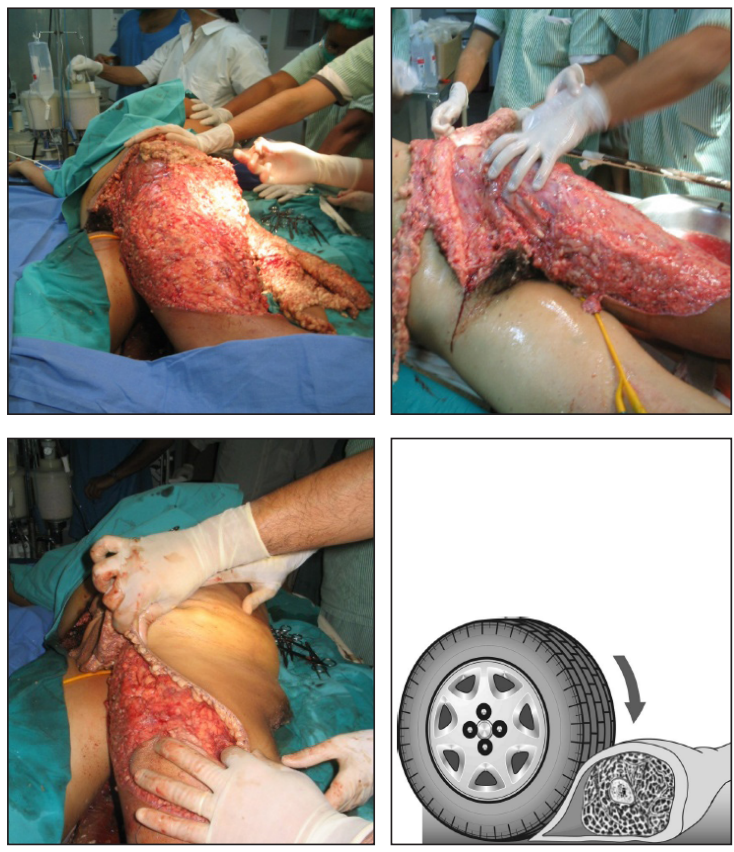

Figura 05. Variante aberta do descolamento de Morell Lavallé. Lesão típica por tração da pele produzida pela roda do veículo. 
a identificação do veículo. A gravidade do atropelamento pode ainda causar lesões viscerais, rotura de vísceras ocas e lacerações em órgãos maciços[2,3].

Como forma de minimizar estas lesões, determinados veículos de trajeto obrigatório, possuem dispositivos dianteiros de forma a empurrar a vítima para fora do seu trajeto, produzindo algumas escoriações típicas [4].

3. Arrastamento: No seguimento das fases anteriores a vítima pode permanecer presa ao veículo sendo arrastada por este. Relaciona-se com o impulso que o veículo lhe transmite durante a fase do choque. As lesões são características nas faces expostas ao atrito com o solo, podendo alternar com áreas protegidas pelas vestes, conhecidas como escoriações em saltos. São escoriações tipo placas de arrasto de aspecto apergaminhado quando desidratadas pelo fenómeno postmortem.[14,15]
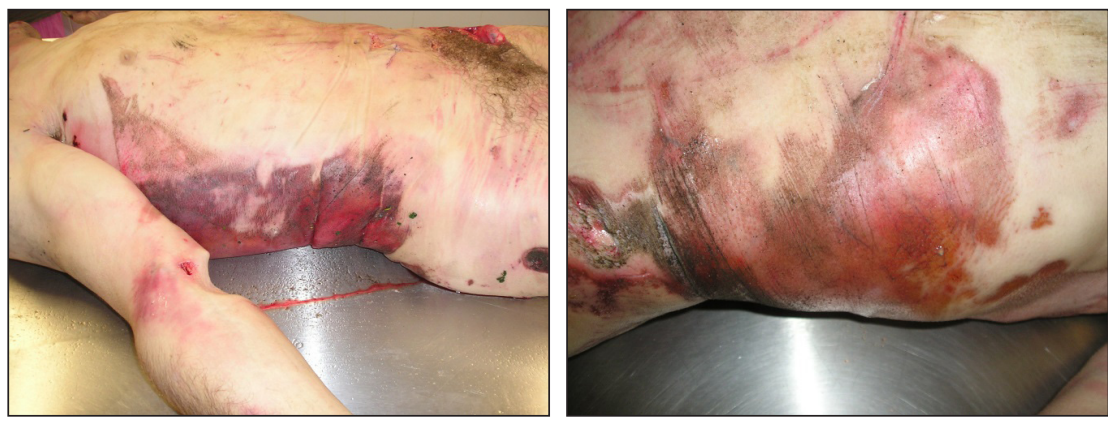

Figura 06. Escoriações típicas produzidas pelo arrasto no solo, o aspecto apergaminhado ocorre pela desidratação da pele.

\section{Atropelamento incompleto}

As fases descritas, que compõem o atropelamento típico só são encontradas quando o peão se encontra de pé. Existem situações em que faltam algumas fases, sendo assim um atropelamento incompleto; as variedades mais frequentes são:

1. Quando a vítima já está no chão (suicídios, homicídios, mal súbito). As fases de choque e queda estão ausentes, iniciando o complexo lesional pelo esmagamento.

2. Nos casos em que a vítima esta de pé no momento do embate inicial, este pode ser reduzido ao choque e queda apenas, faltando as duas 
últimas fases, devido a massa leve do veículo, ou a alta velocidade, que projeta a vítima a distância, afastando-a do seu caminho.

3. O arrastamento é aleatório, pois depende da existência de uma parte que sobressai do veículo e arraste a vítima, ou de que a roupa da vítima fique presa a alguma peça do veículo.

4. Alguns atropelamentos podem apresentar somente uma fase isolada dificultando a interpretação.

\section{Trajetórias típicas do atropelado}

As trajetórias de acordo com o segundo impacto, acima ou abaixo do centro de gravidade do peão podem ser agrupadas de acordo com Ravine em cinco trajetórias básicas, "wrap, forwardprojection, fender vault, roofvault e somersault". Becker, acrescenta mais uma modalidade, "dragging"[4].

1. Projeção frontal - forwardprojection: Como segundo impacto é acima do centro de gravidade, o peão é projetado para a frente. Ocorre com as crianças atropeladas por automóveis ou por adultos atingidos por veículos de frente alta. Numa segunda fase o veículo tende a passar sobre o peão.

2. Montagem sobre o capô - wrap: É a mais comum das trajetórias e ocorre com o veículo, normalmente em desaceleração. Quando o segundo impacto do veículo com o peão ocorre em ponto acima do ponto inicial e abaixo do centro de gravidade, aumentando a velocidade de rotação no sentido anti-horário imposta pelo primeiro contato, determinando o pivoteamento do corpo ao redor da zona do segundo contato, comumente o extremo superior dianteiro do veículo, fazendo com que a parte superior do corpo atinja o capô, contra o qual se amolda momentaneamente, como se o abraçasse, daí o nome em inglês wrap. O sentido anti-horário da rotação, portanto contrário à trajetória do veículo intensifica o choque, fazendo com que a parte superior do corpo permaneça em grande contacto com o capô, até que se separa do veículo devido a desaceleração deste, seguindo-se a projeção para a frente.

3. Passagem pelo pára-lama - fender vault: O peão atropelado projeta-se sobre o pára-lama, caindo lateralmente na trajetória do veículo. Normalmente ocorre quando a pessoa é atingida pelas extremidades da parte frontal, impactos parciais ou quando dotada de alguma velocidade, atravessando a via, andando apressadamente ou conjugada com a velocidade do veículo, determinando um movimento lateral secundário. 

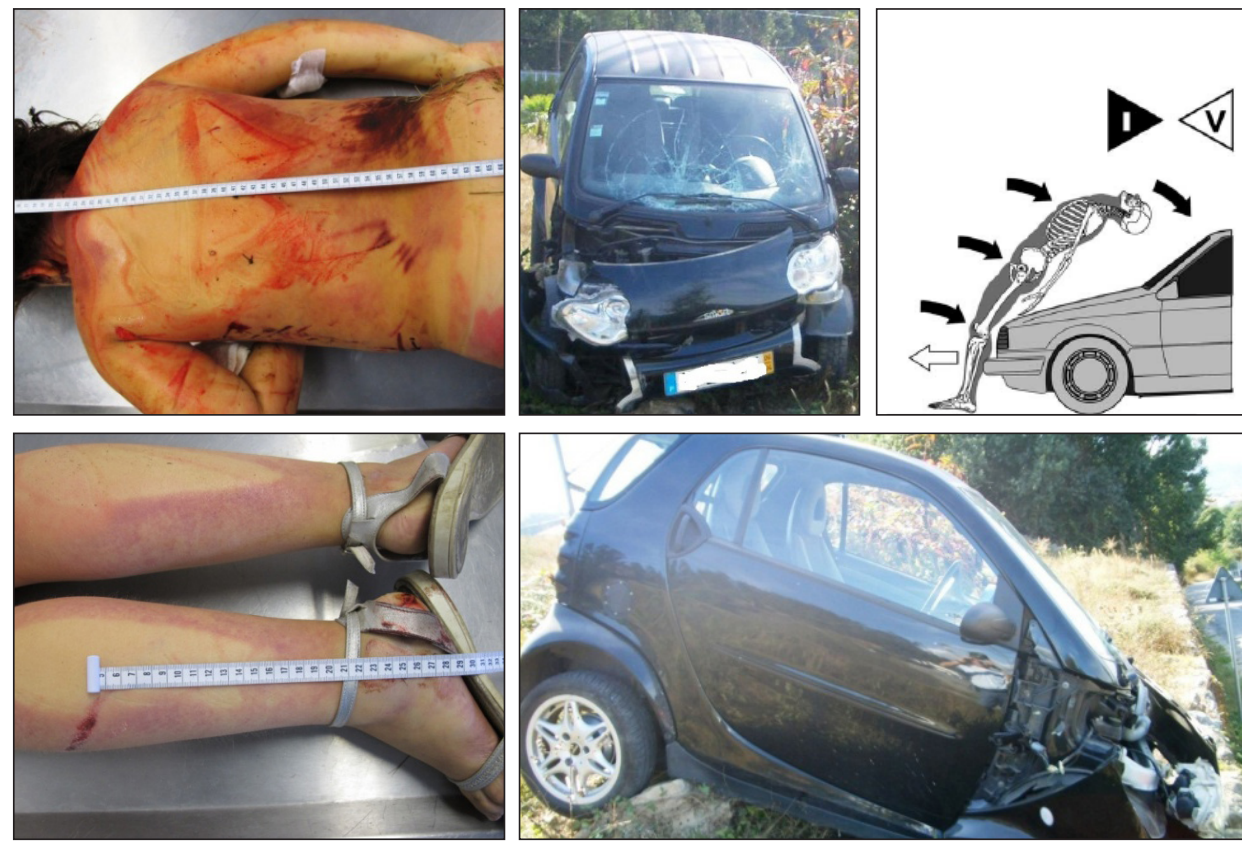

4. Passagem sobre o teto - roofvault: é encontrada quando o veículo tem a frente rebaixada, e o centro de gravidade do peão fica um pouco mais elevado, quer esteja em aceleração ou desaceleração e, ainda, quando o veículo desenvolve maiores velocidades. No caso, o primeiro contato por baixo do centro de gravidademaximiza a velocidade de rotação no sentido anti-horário. Assim o peão é projetado para trás, sobre o teto ou mesmo sobre a parte traseira do veículo.

5. Salto mortal - sommersault: É uma variação do wrap. Ocorre com velocidades mais elevadas ou com impacto de veículo com frente rebaixada contra os membros inferiores, produzindo a descrição de uma trajetória circular no ar.

\begin{tabular}{|l|l|l|}
\hline Trajetória cinemática & Frequência relativa & Velocidade média do impacto \\
\hline Wraptrajectory & $42,2 \%$ & $30 \mathrm{~km} / \mathrm{h}$ \\
\hline Forwardprojection & $34 \%$ & $20 \mathrm{Km} / \mathrm{h}$ \\
\hline Fender vault & $13,3 \%$ & $40 \mathrm{~km} / \mathrm{h}$ \\
\hline Roofvault & $5,4 \%$ & $60 \mathrm{~km} / \mathrm{h}$ \\
\hline Somersault & $1,7 \%$ & $60 \mathrm{~km} / \mathrm{h}$ \\
\hline
\end{tabular}

Fonte: SAE Society of Automotive Engineers Apud. Ranvier Aragão in Acidentes de trânsito[4] 

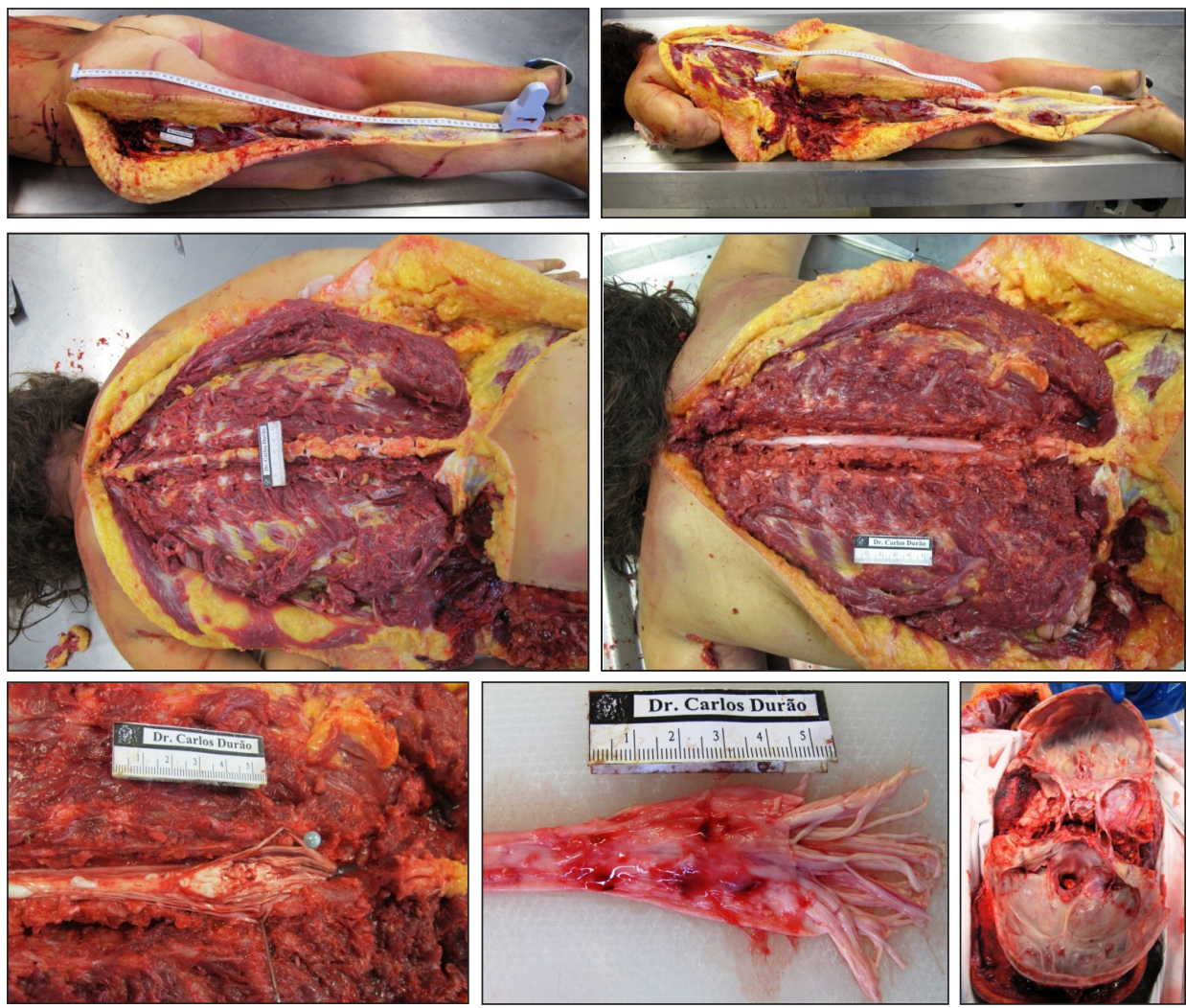

Figura 07. Criança vítima mortal de atropelamento. É possível perceber após dissecção profunda dos planos, o impacto primário nos membros inferiores, o impacto secundário na região lombosagrada e o traumatismo craniano. As lesões na vítima correlacionam-se com os danos no veículo. Detalhe da infiltração hemorrágica na medula e da fratura da base do crânio em dobradiça, típica de embates laterais.

\section{Vestígios de atropelamento}

A reconstrução de um acidente de viação é feita pela observação de alguns elementos fundamentais. As leis de Newton constituem uma base para a compreensão dos comportamentos estáticos e dinâmicos dos corpos materiais. Na terceira lei, Newton mostra nos que em toda a ação, há sempre uma reação oposta e de igual intensidade. Se o automóvel colide com uma vítima, esta colide contra o automóvel com a mesma velocidade, deixando nele a sua marca. Todo o contato deixa uma marca. Este é o pilar de toda a ciência forense. Esta é a teoria do médico, discípulo de Lacassagne e pioneiro na criminalística, Edmond Locard, baseada no princípio da transferência. 
O local onde se estabelece o embate pode esclarecer algumas causas, como características da via, condições climatéricas, falhas estruturais, presença de animais, ausência de sinalização. Marcas de travagem, fragmentos de vidro ou partes do automóvel, além das manchas de sangue e os pontos de repouso do veículo e da vítima, são elementos importantes a serem observados no local e que ajudam a esclarecer, por exemplo, se a vítima foi arrastada ou projetada. Razão pela qual o local deve ser,sempre que possível, preservado[2,4,9].

A observação do veículo, além das buscas por avarias que justifiquem uma falha mecânica, pode evidenciar elementos da vítima como cabelos, sangue, osso e fragmentos da roupa, que determinam o encontro deste com a vítima, passo essencial no casos de Hit andrun. As deformações do veículo podem permitir estabelecer uma estimativa da velocidade deste, mas é preciso ter em mente que nem todos os danos são evidentes, principalmente quando existe tamanha desproporcionalidade entre veículos pesados e a vítima.É um tema exaustivamente estudado pela física dos acidentes em engenharia forense, que tem ganho cada vez mais protagonismo e em que, para um completo exame, as descrições na vítima são fundamentais.
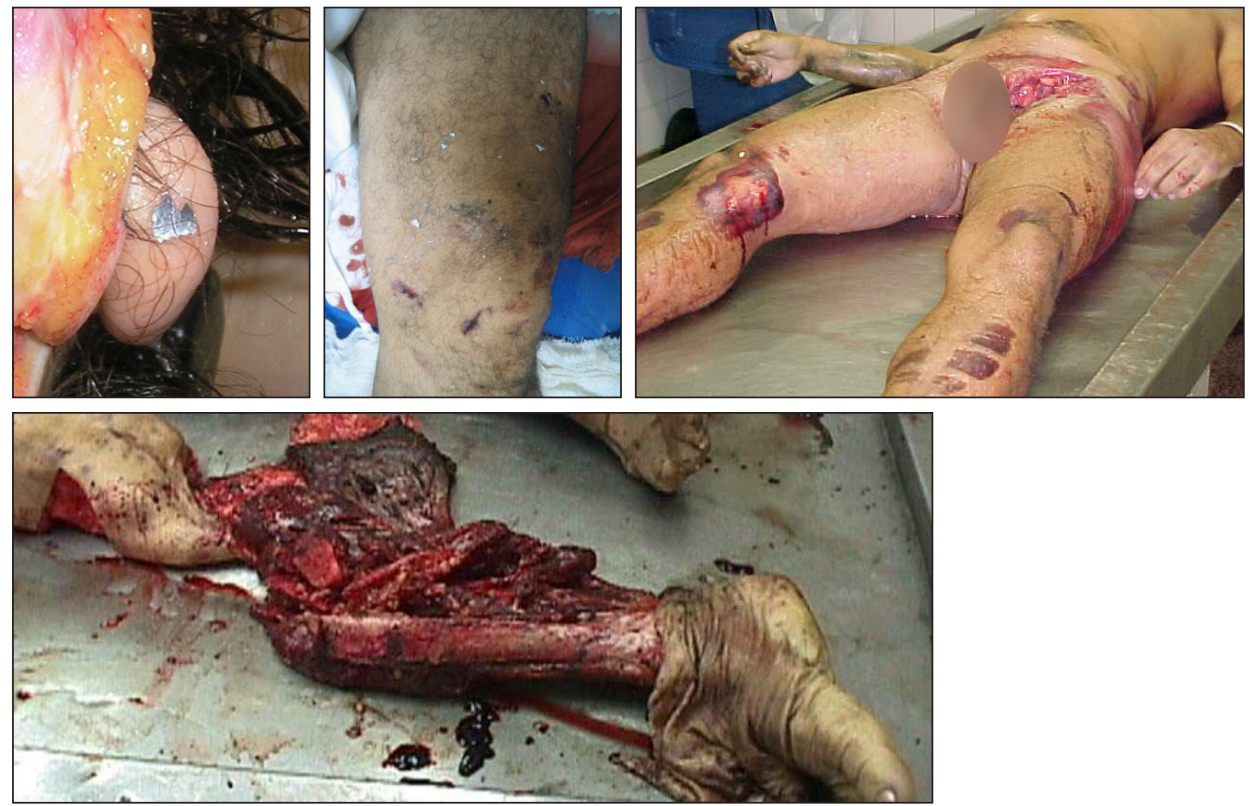

Figura 08. Assim como manchas de sangue e restos de tecidos podem ficar no veículo, fragmentos de tinta frequentemente ficam aderidos na vítima, podendo identificar a cor do veículo em fuga. A velocidade pode ser estimada a partir do encontro de lesões por tração da pele, que costumam produzir lacerações na região inguinal. A acção da roda durante a travagem pode gerar esmagamento associado ao desluvamento dos membros. 


\section{Descrições das lesões nas vítimas de atropelamento}

Quando um peão é atingido por um automóvel, a gravidade e suas lesões, variam de acordo com vários fatores, entre os quais se destacam: a velocidade do veículo; se ocorrem ou não travagens; características físicas do veículo e da vítima, independentemente de se tratar uma criança, um adulto ou um idoso[3].

\section{Relação entre a velocidade do impacto e as lesões}

A velocidade do veículo é provavelmente o fator mais determinante nas lesões. Entre os $20 \mathrm{~km} / \mathrm{h}$ a $40 \mathrm{~km} / \mathrm{h}$, a natureza das lesões começa a agravar-se[3]. O que não quer dizer que lesões muito graves não possam ocorrer a baixa velocidade. Observações em vítimas fatais de atropelamentos permitem identificar alguns tipos de lesões relacionadas a velocidade do impacto:

1. Traumatismos crânio encefálicos

2. Fraturas da coluna

3. Rupturas da aorta

4. Lesão cutânea da região inguinal com ou sem fraturas da bacia

5. Amputações e fraturas dos membros

O traumatismo craniano é a principal causa de morte nos acidentes de viação. Traumatismos de alta energia podem produzir fraturas do crânio, sendo a fratura da base do crânio, em "fratura em dobradiça", a mais comum nos impactos laterais[2,3]. Mas é importante lembrar que grande parte das hemorragias encefálicas não está associada a fraturas, principalmente na população mais idosa.

As fraturas da coluna são na grande maioria fraturas cervicais, por aceleração e desaceleração súbitas, gerando movimentos de hiperextensão ou hiperflexão. A fraturada apófise odontóide com lesão medular assim como a dissociação atlântooccipital são frequentes achados necroscópicos. Di Maio descreveu que surgem lesões cervicais a partir dos $27,5 \mathrm{~km} / \mathrm{h}$, sendo comum acima dos $45 \mathrm{~km} / \mathrm{h}$ e quase sempre presentes acima dos $67,5 \mathrm{~km} / \mathrm{h}[2]$. Sanchez Vera descreve lesões medulares a partir dos 120 a 140km/h[5]. Huelke e Gikas estabeleceram uma relação entre o perímetro torácico e fraturas nesta área, apontando o aumento do perímetro torácico como uma ligeira proteção deste[16].

Em todas as situações em que o sentido do trauma não é estritamente antero-posterior, pode ocorrer um mecanismo rotacional na coluna cervical, na medida que o centro de gravidade da cabeça não coincide com a articulação 
atlanto occipital. Quanto mais lateralmente o trauma atingir a vítima, maior a torção sobre a coluna cervical, motivada pelo movimento oscilatório para o lado em que atua a força. Razão que torna o traumatismo lateral mais grave que os ântero-posteriores[17].

Nos acidentes de alta energia são frequentes fraturas vertebrais em vários segmentos, sendo as regiões da transição toraco-lombar e cervico-torácica vulneráveis. Os arcos costais são mais resistentes nos traumatismos antero-posteriores do que nos traumatismo laterais, dissipando energia e protegendo os corpos vertebrais articulados a grade costal. Fraturas múltiplas de arcos costais podem constituir "volet costal" e merecem especial atenção aquando da sua observação.

O traumatismo torácico por aceleração súbita, produz uma lesão por secção da aorta após a sua curvatura, quando o coração é livremente projetado para frente, sendo contido por um ponto fixo da aorta. Quando a lesão é total a morte é imediata mas nas secções parciais pode surgir um aneurisma periaórtico, facilmente reconhecido no Rx. Nestes casos, a vítima poderá ser salva se for prontamente diagnosticada e intervencionada[18,19].

A importância do conhecimento da biomecânica do trauma é notória na previsão das lesões associadas (coração e pulmões) após traumatismos na coluna que podem incidir sobre diversas lesões com gravidade variável. Fica claro que nas lesões mais graves com lacerações dos grandes vasos a vítima acaba por morrer no local, mas é inaceitável que nas pequenas lacerações o doente morra por hemorragia que tenha passado despercebida, após diversas horas dentro de uma unidade hospitalar à espera de avaliação pelo Ortopedista, sem que se tenha feita a adequada avaliação pela Cirurgia Geral ou outro médico responsável pela sala de trauma.

Erros na triagem podem condicionar a diferença entre o sucesso de um atendimento e o seu completo fracasso. Lesões potencialmente mortais devem ser lembradas, ou melhor, jamais esquecidas. Frequentemente graves lesões viscerais, vasculares ou encefálicas estão presentes sem aparentes lesões externas. Um estudo comparando índices de lesões do joelho, anca e coxa com lesões de vísceras abdominais em vítimas de acidentes de viação mostrou que as vítimas com lesões osteoarticulares apresentavam uma probabilidade quatro vezes menor de sofrerem lesões abdominais graves, o que é explicado pela dissipação da energia durante a fratura[20]. Embora uma fratura exposta seja uma emergência em ortopedia, esta é, sem dúvida, menos ameaçadora à vida do doente, do que uma lesão abdominal grave, exceto claro, nas hemorragias sem controle.

Roupas resistentes, principalmente no inverno, e terrenos mais macios podem amortecer a queda ou proteger a pele de lesões externas, mas são incapazes de evitar lesões por aceleração e desaceleração súbita. A história do evento 
deve ser sempre valorizada para a correta triagem e abordagem das vítimas nos acidentes de viação, incluindo os atropelamentos, conforme o preconizado pelo ATLS, no nosso país tutelado pelo Colégio Português de Cirurgia.

A clássica lesão estriada na região inguinal por tração da pele ocorre ainda segundo Di Maio, a partir dos $66 \mathrm{~km} / \mathrm{h}$ e quase sempre estápresente, acima dos $95 \mathrm{~km} / \mathrm{h}$. Acidentes de alta energia ou com veículos de frente alta, estão relacionados com lesões do anel pélvico, sendo a gravidade proporcional a energia associada. Amputações ocorrem acima dos $98 \mathrm{~km} / \mathrm{h}$, mas estas vão depender essencialmente do tipo de atropelamento. Pode ocorrer esmagamento dos membros inferiores em acidentes com baixa energia[2,3].
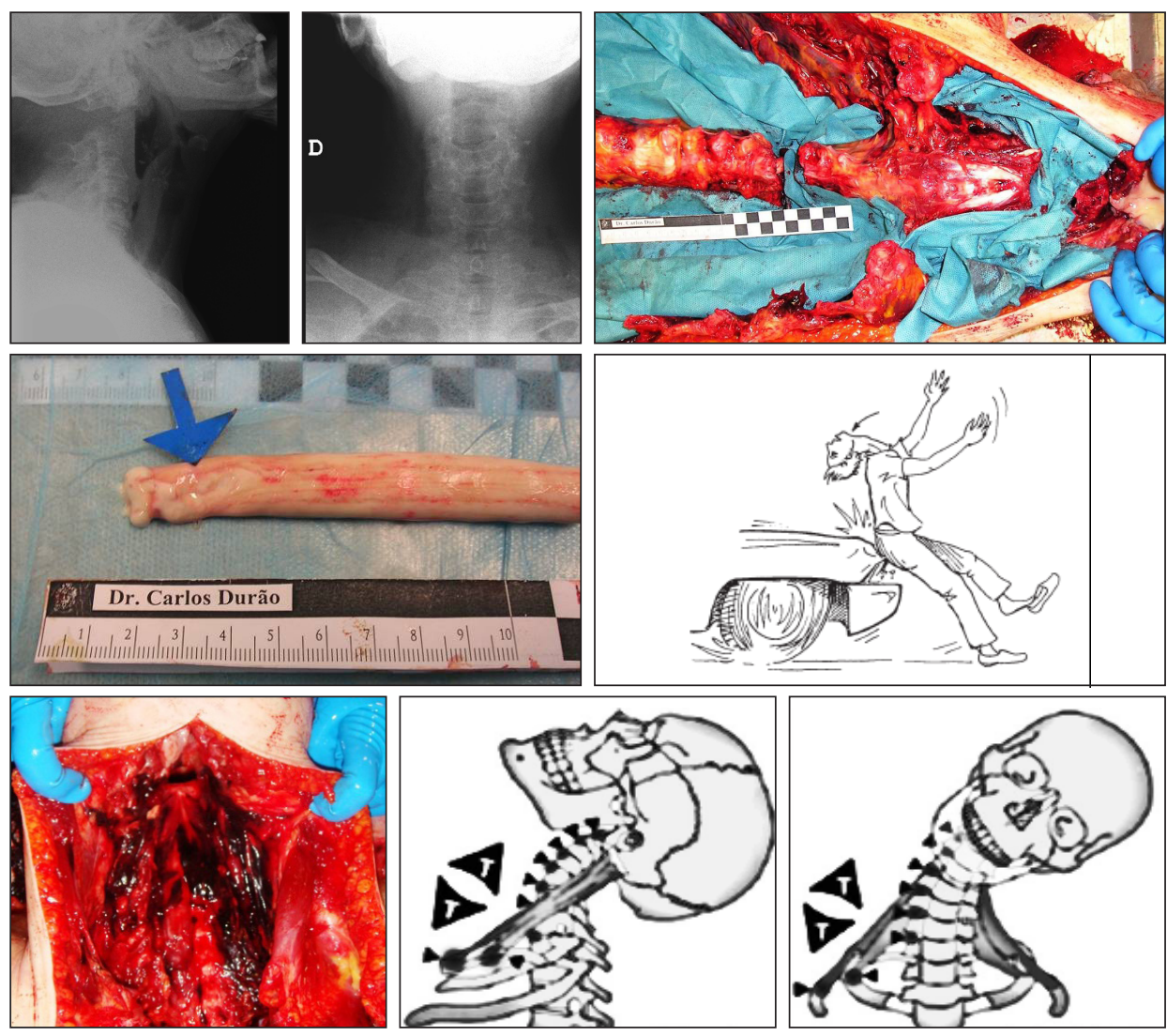

Figura 09. As fraturas da coluna são em sua grande maioria fraturas cervicais, por aceleração e desaceleração súbitas, gerando movimentos de hiperextensão ou hiperflexão. A fratura daapófise odontóide com lesão medular assim como a dissociação atlântooccipital são frequentes achados necroscópicos. 


\section{Conclusão}

Para que possamos tratar adequadamente uma patologia é necessario o conhecimento da história natural da doença, ou seja, a sua evolução e o seu desencadeamento desde o evento inicial até sua morbi-mortalidade, para que se possa de forma eficaz alterar o seu desfecho letal. Não há dúvidas de que o Trauma continua a ser a doença do século, responsável pela morte de uma população jovem e economicamenteativa. $\mathrm{O}$ estudo das lesões mortais, propicia o desenvolvimento de equipamentos de segurança mais eficazes[21,22,23,24] e permite o reconhecimento de lesões potencialmente fatais, estimulando uma intervenção médica precoce e bem sucedida.

Tratando-se de segurança rodoviária, o papel da prevenção de novos acidentes também inclui uma investigação médico-legal sobre eventuais responsáveis. Nestes casos, algumas lesões que poderiam ajudar nas investigações são perdidas por mera ignorância das equipas hospitalares ou pela falta de documentação e coordenação entre equipas médicas e forenses.

\section{Agradecimentos}

Ao Dr Rui Pinto, Director de serviço do Hospital de São João e ao Dr Pedro Afonso, Director do Serviço do Hospital de Vila Franca de Xira, pelo cuidado e atenção com que receberam o $1 .^{\circ}$ autor nos Serviços que superiormente dirigem, disponibilizando meios e recursos essenciais no estudo da traumatologia.

\section{Referências bibliográficas}

1. Calabuig G.J, Verdú P.F. Accidentes de Tráfico. In: Calabuig G.J. Medicina Legal y toxicología. $6^{a}$ edición. Barcelona: 2005. p.371-378.

2. GSpitz WU, Russell SF. The road traffic victim. In: Medicolegal investigation of death: guidelines for the application of pathology to crime investigation. 2nd ed. Thomas Books Illinois; 1980:377-405.

3. Di Maio V.J. Dominick J. Deaths caused by motor vehicle accidents. in Forensic pathology. $2^{\mathrm{a}}$ ed. CRC press. 2001.

4. Aragão R.F. Acidentes de trânsito, análise pericial. $4^{\text {a }}$ edição Ed. Millenium. Campinas 2009.

5. Vacaflor S.P. Exame necroscópico nos acidentes de trânsito terrestres. In Manual de medicina legal. Vanrell J.P. 4a edição. Ed. Mizumo. São Paulo 2011.

6. Burgess AR, Poka A, Brumback RJ, et al. Pedestrian tibial injuries. J Trauma 1987; 27: 596-601.

7. Durão C.H. Marta M. Pinto. R. Cabral T. Vieira D. N. Aplicações forenses do estudo de lesões do pé e tornozelo. Livro de Resumos do XXX Congresso Nacional de Ortopedia e Traumatologia da SPOT. Volume 18. 1. 2010. 
8. Teresínski G. Injuries of the thigh, knee, and ankle as reconstructive factors in road traffic accidents. In Rich J. Dean. E in Forensic Medicine of the Lower extremity. Human press. New Jersey 2005.

9. MJ Dodd, Traffic Deaths. In Encyclopedia of forensic sciences. Three volume, 1-3. London. UK. 2000.p.353-358.

10. Porta D, Kress T, Fuller P, Snider J. Fracture studies of male and female cadaver tibias subjected to anterior or lateral impact testing. The FASEB Journal 11:A622 (1997).

11. Messerer OM. ÜberElastizität and Festigkeit der menschlichenKnochens. Stuttgart: JG Cotta Verlag;1880.

12. Durão C.H. Lesões ortopédicas da coxa, joelho e tornozelo como meio de reconstrução dos acidentes de viação. Livro de Resumos do XXX Congresso Nacional de Ortopedia e Traumatologia da SPOT. Volume 18. 1. 2010.

13. Durão C.H. Variante aberta do descolamento traumático de MorellLavallé. Livro de Resumos do XXVIII Congresso Nacional de Ortopedia e Traumatologia da SPOT. Volume 16. 1. 2008

14. França G.V Medicina Legal. $9^{\circ}$ edição. Ed. Guanabara Koogan,Rio de janeiro 2011.

15. Hércules, H.C. Medicina Legal-Texto e atlas. Ed. Atheneu. Rio de Janeiro. 2005.

16. Huelk,D.F.,Gikas P.W. investigations of fatal automobile accidents from the forensic point of view. J. Forensic Sci., 11(4), 475-484, 1966.

17. Leme F.P. Biomecânica do trauma. In Trauma a doença dos séculos. FreireE. Ed Atheneu. Rio de Janeiro. 2001. p.269-290.

18. Karger B, Teige K, Bühren W, DuChesne A. Relationship between impact velocity and injuries in fatalpedestrian-car collisions, Int J Legal Med 113:84-88 (2000).

19. Marimont J.V. posterior hip dislocation associated with acute traumatic injury to the thoracic aorta: a previously unrecognized injury complex. J Orthop. Trauma 4: 383. 1990

20. Lee J. Conroy C. Injuries pattern in frontal crashes: the associations between knee-thigh- hip (KTH) and serious intra-abdominal injury. Acidente and analysis and prevation. Elsevier. USA.

21. Porta D, Frick S, Kress T, et al. Spiral fracture: definition and determination of torsional direction from radiographs. Proceedings of the American Academy of Forensic Sciences 2:146 (1996).

22. Porta D, Kress T, Fuller P, Snider J. Fracture studies of male and female cadaver tibias subjected toanterior or lateral impact testing. The FASEB Journal 11:A622 (1997).

23. Teresi'nski G, M,adro R. Knee joint injuries as a reconstruction parameter in car-to-pedestrian accidents.ForensicSciInt 124:74-82 (2001).

24. Teresi'nski G, M,adro R. Ankle joint injuries as a reconstruction parameter in car-to-pedestrian accidents.ForensicSciInt 1118:65-73 (2001). 
Resumo: Aspectos forenses das lesões ortopédicas nos atropelamentos.

Os acidentes de viação constituem um problema de saúde pública. Os atropelamentos são responsáveis pelo maior número de mortes e pelas lesões osteo-articulares mais incapacitantes. As sequelas que daí resultam, oneram o sistema de saúde e as seguradoras com tratamentos dispendiosos, exigem reabilitações lentas e implicam indemnizações pesadas. Estudos biomecânicos têm assumido um papel relevante na prevenção de novas lesões, no desenvolvimento de mecanismos de segurança e na reconstrução dos acidentes.

Nos países com baixo índice de desenvolvimento, peões e veículos dividem o mesmo espaço. A percentagem de peões entre as vítimas dos acidentes de viação, representa um dos marcadores de segurança rodoviária.

Este trabalho relembra conceitos periciais, mecanismos de atropelamento e subsequentes lesões, estabelece um elo de ligação naquilo que o ortopedista observa na urgência e o especialista em medicina legal na autópsia. Alerta ainda para as lesões graves que não são diagnosticadas atempadamente e que podem ter sérias implicações na vida do sinistrado e responsabilização pelo mau desempenho clínico.

Palavras-chave: Reconstrução dos acidentes de viação; atropelamento.

Summary: Road traffic accidents (RTA) are a serious public health problem being pedestrians the ones with the highest rate of death and disability. RTA are responsible for complex fractures that challenge the orthopaedic surgeon as well as burden the healthcare systems and insurers with costly treatments, long rehabilitation periods and often requiring compensation.

Biomechanic studies have a relevant role in injury prevention, in developing safety mechanisms and in accident reconstruction. One of the distinctive landmarks in Road Safety is the percentge of pedestrians victims of RTA considering that in countries with low developing indexes pedestrians and vehicles share the same space.

This paper presents concepts from expert forensics: the main mechanisms of collision between vehicles and pedestrians and it's corresponding injuries, establishing a link between what an orthopaedic surgeon observes in the emergency department and what the coroner verifies in autopsy and tries to bring to our attention serious injuries that go undiagnosed in time.

Key-words: Road traffic accidents; bumper fracture; Messerer fracture. 